ORIGINAL ARTICLE

\title{
Hyperopia and educational attainment in a primary school cohort
}

\author{
W R Williams, A H A Latif, L Hannington, D R Watkins
}

Arch Dis Child 2005;90:150-153. doi: 10.1136/adc.2003.046755

See end of article for authors' affiliations .....................

Correspondence to: Dr A Latif, The Children's Centre, Royal Glamorgan Hospital, Llantrisant, CF72 8XR; Abbas.latif@pr-tr. wales.nhs.uk

Accepted 7 July 2004

\begin{abstract}
Background: Vision screening addresses the visual impairments that impact on child development. Tests of long-sightedness are not found in most school screening programmes. The evidence linking mild-moderate hyperopia and lack of progress in school is insufficient, although strengthened by recent findings of developmental problems in infants.

Aims: To report on the relation between hyperopia and education test results in a cohort of primary school children.

Methods: A total of 1298 children, aged 8 years, were screened for hyperopia on the basis of fogging test results. School test results (NFER and SATs) were compared between groups categorised by referral status and refractive error.

Results: A total of 166 (12.8\%) fogging test failures were referred for ophthalmic assessment. Ophthalmic tests on 105 children provided an accurate diagnosis of vision defects, for reference to their education scores. Fifty per cent of the children examined by optometrists required an intervention (prescription change, glasses prescribed, or referral). Mean (95\% CI) NFER scores of children with refractive errors (summed for both eyes) >+3D (98.4, 93.0-103.8, $\mathrm{n}=32$ ) or $>+1.25 \mathrm{D}$ (best eye) (99.3, 93.0-105.6, $\mathrm{n}=26$ ) were lower than the respective scores of children with a less positive refractive state $(104.8,100.7-$ 108.9, $n=43)(103.6,99.7-107.4, n=49)$, the non-referred group, and total sample. The SATs results followed a similar trend. A high proportion of the fogging test failures (16\%) and confirmed hyperopes $(29 \%)$ had been referred to an educational psychologist, and the latter group contributed substantially to the poor education scores.

Conclusions: The results of this study provide further evidence for a link between hyperopia and impaired literacy standards in children.
\end{abstract}

$\mathrm{T}$ he condition of hyperopia (long-sightedness) requires the eyes muscles to double focus when reading at short distance. Inability of the eye muscles to cope with this stress results in poor word definition and impairment of reading. Mild hyperopia $(+2$ to +4 dioptre), common in children, is generally considered not to be a problem unless it interferes with education. ${ }^{1}$ School vision screening in the UK is primarily distance based, on the assumption that the degree of hyperopia that impacts on educational development is identified by testing for visual acuity at distance. The need for near vision tests, undertaken in two thirds of health districts in England and Wales in 1984, is linked to the indeterminate effect of hyperopia on learning. ${ }^{2}{ }^{3}$ There are also concerns about the effectiveness of current preschool screening services. ${ }^{45}$ The lack of consensus among practitioners in respect of vision screening standards and protocols is international in its dimension. ${ }^{6-10}$

The visual efficiency problems that may impact on learning potential include eye discomfort, inattention, task avoidance, and the development of a harmful association between eye discomfort and learning activities. ${ }^{11}$ The inadequacy of school vision screening tests for detecting learning related vision problems ${ }^{11}$ is increasingly being expounded by the charities concerned with vision, in concert with an increasing number of optometrists placing website advertisements. However, if there is truth in the statement that even mild hyperopia or anisometropia may be problematic for children's education, this has important economic consequences. The present study was undertaken to report on the efficiency of the school vision screening programme in Rhondda Cynon Taff in respect of undiagnosed hyperopia, and investigate educational progress in children with normal and defective sight.

\section{METHODS}

\section{Vision screening}

The community paediatric service in Rhondda Cynon Taff provides a conventional vision screening programme. This programme comprises of distance visual acuity at 7-8 years (Snellen Chart at 6 metres), with referral of children with vision of $6 / 9$ or worse in either eye to an orthoptist (under 8 years) or optometrist (over 8 years). A colour vision screening test on boys at 11-12 years is offered on a demand bases. The preschool programme provides for the selective vision screening of a high risk population (squint, defective visual acuity, or relevant family history-squint, patching or squint surgery, glasses under 8 years in siblings, parents, aunts, uncles, cousins, grandparents) by an orthoptist.

Over 2000 children in Year 3 are vision tested annually at 8 years of age. The present study is on one cohort of approximately 2400 children. Vision screening was undertaken by the school nurses, on all children presenting during June-July 2002. Information about the research component and a parental consent form was distributed along with the letter routinely sent to parents, prior to the school screening programme. There were no exclusions from the study other than for non-consent. The usual vision screening protocol was revised to include a test (fogging test) for hyperopia, and the school nurses received additional training from the optometrist. Mechanisms were introduced to facilitate referral and retrieval of the refraction data for analysis.

Abbreviations: CSI, core subject indicator; NFER, National Foundation for Education Research; RE, refractive error; SAT, standardised assessment test 


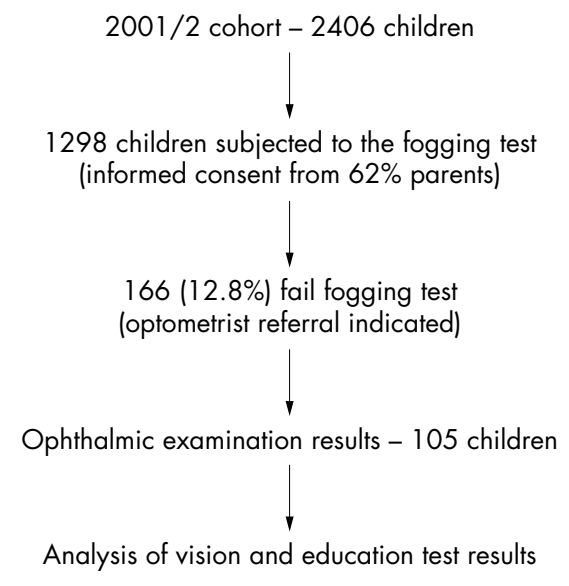

Figure 1 Vision screening and educational assessment components of the study.

Ethical approval was obtained from Bro-Taf LREC. Figure 1 shows the data collection processes pertaining to this study.

The technique of inhibiting accommodation with + lenses (fogging) is used extensively by optometrists during retinoscopy. ${ }^{12}$ Vision is blurred by creating an artificial myopia, which any ciliary contraction (accommodation) makes worse. For distance objects, a +2 lens will produce a 2 dioptre (D) fog in emmetropes, equivalent to a 2D myope fogged for distance with a plano lens. In hyperopes, accommodation is necessary to produce a focused image at distance and near; visual acuity improves with a + lens. The fogging test is, therefore, of use as a screening tool for hyperopia, ${ }^{13}$ and may be used in conjunction with the Snellen Chart. As the amplitude of accommodation is high in children of this age, the lens strength was selected to take account of this. A $+4 \mathrm{D}$ lens was used on the basis that children with more than slight hyperopia would be unable to relax their accommodation sufficiently to see through a lens of this strength. The fogging test was set up to detect a gross change, so that those failing it had a high probability of requiring spectacles.

The $+4 \mathrm{D}$ lenses were fitted into spectacle frames and children were tested with both eyes open, prior to the routine distance reading test. Those able to read any of the letters on the Snellen Chart through the spectacles failed the fogging test, and were referred in the usual way. Parents were advised by letter to take their child to an optometrist, along with a form stating the reason for referral. In this case, the form stated "failed fogging test (+4D lens)". Optometrists were asked to return the vision test results, including the refraction errors in prescription form. Anisometropia (difference in refractive power of the eyes) is set as equal to or greater than $1 \mathrm{D}$.

\section{Educational assessment}

Standardised assessment tests (SATs) and NFER (National Foundation for Education Research) Progress in English (NFER-Nelson, UK) tests are undertaken routinely by children during their formal education in Rhondda Cynon Taff schools. SATs measure progress in the national curriculum of English, mathematics, and science. Key Stage 1 , undertaken by 7 year olds, is primarily assessed by teachers at eight levels of difficulty. The majority of pupils are expected to attain at least level 2 in each subject, in combination (the core subject indicator, CSI). One way of measuring educational standards at school and regional level is by the proportion of children achieving the CSI. The NFER test assesses reading and writing skills, and generates a raw score that is standardised for age. Age adjusted NFER scores range from 70 (low achievement) to 140 (high achievement), a score of 100 being the norm.

SATs and age adjusted NFER results were obtained for all consenting children when they were available (1208 and 1079 respectively). The former figure for the national test represented $93 \%$ of the consenting children. The missing data included children who were disapplied, absent, or working outside the test standard. There were fewer results available for NFER tests, which were not taken in every school. The coordinator for special needs and the educational psychologist also provided information on children who had been referred to their care, independently of the vision screening results.

\section{Data analysis}

Vision screening and school test data were entered into an SPSS file for statistical analysis. Fogging was undertaken solely to screen for hyperopia and referral, and not to categorise the referred children for analysis of data. Categorisation was based on refractive errors (RE) and published evidence of significantly lower test scores in children with RE exceeding +1.25D. ${ }^{14}$ The main analysis was undertaken on the two groups of children with combined RE for both eyes equivalent to +3.0D or less $(\leqslant+3 \mathrm{D})$, or exceeding +3.0D $(>+3 \mathrm{D})$. For the most sensitive assessment test (NFER) further analysis was undertaken, to investigate the effects of psychologist referred children, and categorise data on the basis of RE in the best eye $(+1.25 \mathrm{D}$, and $+1.5 \mathrm{D}$ ), which may be more relevant to the impact of hyperopia on education. Between group differences were analysed through the use of confidence intervals, one way ANOVA, and the $\chi^{2}$ test. Spearman's correlation test was used to explore the relation between anisometropia and NFER score.

\section{RESULTS}

\section{Vision screening}

A total of $1298(62 \%)$ of the children participating in the vision screening programme were given a fogging test following parental consent ( $51 \%$ male, $49 \%$ female). Of the 215 children referred, 166 were fogging test failures and the others (non-fogging test failures) failed to meet $6 / 6$ criteria. The fogging test failure rate was $12.8 \%$ (57\% male, $43 \%$ female). Initially, prescription forms for $30 \%$ of the fogging test failures were returned. Follow up letters showed that approximately $4 / 5$ ths of parents had already taken their child to an optometrist and the remainder intended to visit. Optometrists $(\mathrm{n}=22)$ and orthoptists $(\mathrm{n}=2)$ were later contacted by letter or phone to obtain missing test results.

\section{Ophthalmic assessment}

Ophthalmic records of 105 fogging test failures were obtained, and these included RE for 104 children (table 1). Three of the fogging test referrals were borderline myopes and have been excluded from the analysis. There were eight anisometropes in the $\leqslant+3 \mathrm{D}$ group (largest difference $+1.75 \mathrm{D}$ ) and 21 in the $>+3 \mathrm{D}$ group (largest difference $+4.0 \mathrm{D})$. There was no correlation between anisometropia and NFER score for the fogging test referral group $(r=0.05$, $\mathrm{n}=21$ ). The optometrists' intervention rate in the $>+3 \mathrm{D}$ group was $76 \%$, in comparison to $32 \%$ in the $\leqslant=+3 \mathrm{D}$ group. The prescribing of + lenses started at $\mathrm{RE} \geqslant+0.75 \mathrm{D}$ in the $\leqslant+3 \mathrm{D}$ group. The weakest binocular $\mathrm{RE}$ observed in the $>+3 \mathrm{D}$ group of fogging failures were $+1.5 \mathrm{D}+1.75 \mathrm{D}$, and lenses stronger than +3.25D were prescribed for constant wear. The mean age (SD) at first prescription, calculated from the records of 36 children in this group who had or were prescribed glasses, was 4.4 (2.0) years. Five of the 12 most severe hyperopes (range +4.5 to $+9.0 \mathrm{D}$ ) were prescribed 
Table 1 Ophthalmic assessment of fogging test failures

\begin{tabular}{|c|c|c|c|c|c|c|c|c|}
\hline $\begin{array}{l}\text { Refraction } \\
\text { group* }\end{array}$ & $\mathbf{n}$ & $\begin{array}{l}\text { No problem } \\
\text { identified }\end{array}$ & $\begin{array}{l}\text { Glasses } \\
\text { satisfactory }\end{array}$ & $\begin{array}{l}\text { Prescription } \\
\text { changed }\end{array}$ & $\begin{array}{l}\text { Glasses } \\
\text { prescribed }\end{array}$ & Strabismus & Amblyopia & Referral \\
\hline$+3 D$ or less & 59 & 35 & 5 & 6 & 12 & 5 & 5 & 1 \\
\hline$>+3 D$ & 42 & 2 & 8 & 20 & 12 & 7 & 9 & 0 \\
\hline Total & 101 & 37 & 13 & 26 & 24 & 12 & 14 & 1 \\
\hline
\end{tabular}

glasses between the ages of 5 and 7 years. The strongest new prescription resulting from hyperopia screening was $+3.75+4.5 \mathrm{D}$.

\section{Education test results in vision screened categories}

Sample numbers in the subgroups of tables 2 and 3 do not tally with the total because they relate to the dynamics of complete vision and NFER datasets of individuals. The highest NFER and SATs scores were provided by the $\leqslant+3 \mathrm{D}$ group, whereas the lowest scores were provided by the more strongly hyperopic (NFER) and non-fogging test referrals (SATs). Mean values of the fogging referred groups were outside the confidence interval range for all children, and the group of non-referred children. The distribution of CSI achievement between the non-referred and non-fogging referred groups was significant $\left(p<0.05, \chi^{2}\right.$ test).

Categorisation of hyperopic children on the basis of one eye, increased numbers in the group with least hyperopia; based on RE of $+1.25 \mathrm{D}$, there was an $8 \%$ change in group status. When compared to the groups categorised on the basis of both eyes, NFER scores showed less marked differences between the weakest and strongest hyperope groups. Categorisation based on a $+1.5 \mathrm{D}$ error further reduced the differential between the weakest and strongest hyperope groups (results not shown). A one way ANOVA did not identify significant differences between the test groups.

No children tested by the optometrists were on the Learning Support Service list for an INSTEP assessment (a national curriculum based tool in use in special schools, applied to children working below the national average), or receiving support for a specific learning difficulty such as dyslexia. However, 17 children $(16.0 \%)$ in the group of fogging test failures had been referred to the educational psychologist (a different service to Learning Support). Of children in the $>+3 \mathrm{D}$ group, $12(28.6 \%)$ were listed as referrals. When children on the psychologist's referral list are excluded from analysis, the NFER scores normalised for the more strongly hyperopic group. This was especially evident when children were grouped on the basis of hyperopia in their best eye. Reports, available for seven of the nine children (at 6-9 years of age) in the $>+3$ D group with NFER scores, showed that this group was characterised by minor multi-factorial problems (deficits in esteem, attention con- trol, information and motor processing) that did not qualify for a specific diagnosis but not low IQ scores.

\section{DISCUSSION}

The original cohort of children was reduced in number by the usual non-participation rate of the screening programme. Consent was withheld by almost $40 \%$ of parents, and a similar proportion of parents of the fogging test failures were unresponsive to follow up. Although this may be indicative of parental apathy, our data showing that 39\% of the presenting children had previously visited the optometrist may also have some relevance. The fogging test proved suitable for inclusion in the school vision screening programme; simple and quick to undertake, though requiring administrative time for the referral process.

Our results suggest a prevalence of hyperopia similar to the $5 \%$ rate $(\mathrm{RE}>+2 \mathrm{D})$ reported in Swedish children. ${ }^{9}$ When projected to the $87 \%$ of the cohort that participated in the programme $(n=2094)$, the results generate figures of 105 children with hyperopia in a fogging test referred group of 268. The false positive rate of $36 \%$ for the fogging test seems high, but is not dissimilar to some reported referral rates of children in Sweden and the UK on the basis of visual acuity. ${ }^{15}$ Factors pertaining to the false positive rate may include limited cooperation from young and sometimes shy or nervous children, and mistakes in documentation by the school nurses. One potential test limitation was a false result from an over accommodating child with a high degree of hyperopia unable to relax accommodation during the short test period. We did not investigate the false negative test rate for hyperopia.

Recent developments in the vision screening of children include the use of vision screening computer programs and photoscreening, which have certain advantages in terms of automation, efficiency, and suitability for specific groups of children. $^{16}{ }^{17}$ The computer program, set up to screen for hyperopia $>+3 \mathrm{D}$, requires an additional fogging test when the core test results are ambiguous, whereas photoscreening is poor at detecting hyperopia between +2 and $+3.5 \mathrm{D}$. Hand held autorefractors, which may be operated by lay persons, are expensive, but their reasonable accuracy makes them suitable for screening. ${ }^{18}$

Kohler and Stigmar ${ }^{13}$ concluded that a test for hyperopia could be safely omitted from a screening programme when

Table 2 NFER results for vision test groups

\begin{tabular}{|c|c|c|}
\hline \multirow[b]{2}{*}{ Group } & \multicolumn{2}{|l|}{ NFER, mean $(95 \% \mathrm{Cl})[\mathrm{n}]$} \\
\hline & Complete group & Psychologist referrals excluded \\
\hline $\begin{array}{l}\text { Fogging referred }+3 \mathrm{D} \text { or less } \\
\text { Fogging referred }>+3 \mathrm{D}^{*} \\
\text { Fogging referred }+1.25 \mathrm{D} \text { or less } \dagger \\
\text { Fogging referred }>+1.25 \mathrm{D} \dagger \\
\text { Non-fogging referrals } \\
\text { Non-referred group } \\
\text { All children }\end{array}$ & $\begin{array}{l}104.8(100.7 \text { to } 108.9)[43] \\
98.4(93.0 \text { to } 103.8)[32] \\
103.6(99.7 \text { to } 107.4)[49] \\
99.3(93.0 \text { to } 105.6)[26] \\
100.2(97.0 \text { to } 103.5)[80] \\
103.0(101.6 \text { to } 103.3)[902] \\
102.5(102.0 \text { to } 103.9)[1079]\end{array}$ & $\begin{array}{l}105.3(101.0 \text { to } 109.5)[41] \\
102.7(96.2 \text { to } 109.1)[23] \\
104.0(99.9 \text { to } 108.1)[46] \\
105.1(97.8 \text { to } 112.5)[18]\end{array}$ \\
\hline
\end{tabular}


Table 3 SATs results for vision test groups

\begin{tabular}{lrl} 
Sample & $\mathbf{n}$ & $\begin{array}{l}\text { Proportion attaining } \\
\text { CSI level 2 (\%) }\end{array}$ \\
\hline Fogging referred +3D or less & 45 & 86.7 \\
Fogging referred $>+3 D$ & 39 & 79.5 \\
Non-fogging referrals & 85 & 76.5 \\
Non-referred group & 955 & 85.9 \\
All children & 1208 & 83.9 \\
\hline
\end{tabular}

preschool vision screening was effective. Although study numbers were small, they showed that one quarter of children exceeding $+2 \mathrm{D} \quad(\mathrm{n}=8)$ had moderate learning difficulties in comparison to none in the group with RE below +0.5D $(\mathrm{n}=15)$. Stewart-Brown ${ }^{1}$ and Grisham and Simons ${ }^{19}$ also provided evidence of impaired reading progress in children with mild hyperopia. More recently, Rosner and Rosner ${ }^{14}$ compared academic achievement in schoolchildren $(\mathrm{n}=782)$ with and without vision defects. Significantly lower achievement scores were evident in hyperopic children with RE exceeding $+1.25 \mathrm{D}$. This degree of refraction is relevant to the current study, and may indicate a level of hyperopia below which test scores are not influenced in the control group. The present results show impaired progress in two well established educational tests, differing in content and standardisation, by children with the aforementioned degree of hyperopia, although group numbers are insufficient to show a statistical difference on testing. Furthermore, the psychologist referrals make a considerable contribution to the poor academic performance of the hyperope population.

There is ample evidence, reinforced by the results of this study, that children with specific deviations of RE are better suited to certain tasks. ${ }^{12021}$ The contribution of vision defects, including hyperopia, to the development of disruptive behaviours has been expounded on by Johnson and coworkers. $^{22}$ In this study, the psychologist referral rate of $16.0 \%$ in the fogging failure test group was higher than the general rate for that age group and year $(5.3 \%, \mathrm{n}=3200)$ in the same education authority. The combined effects of hyperopia and minor multi-factorial problems in the children are educationally disadvantageous.

As the eye develops under neurological control, it is not unreasonable to look for a common origin to problems of vision, motor coordination, learning ability, and behaviour, in terms of defective neurotransmission. Atkinson and colleagues $^{23}$ report that significant hyperopia $(>+3.5 \mathrm{D})$ in infants at 9 months is associated with a range of small developmental deficits in the visuocognitive and visuomotor domains that persist to at least 5 years of age. They advocate that hyperopia should be taken into account as a risk factor in the developmental assessment of young children. If this is so, corrective glasses may be insufficient, in the absence of increased educational support, to normalise achievement scores of the hyperope group, although there is some evidence of benefit from this strategy. ${ }^{219}$ Future research should perhaps focus on the hyperopes who are successful academically, rather than on those who are failing, as a means of gaining further insight into the link between hyperopia and progress in education.

\section{ACKNOWLEDGEMENTS}

The authors are indebted to Barbara Palmer, and staff in Community Nursing and the School's Office of Rhondda and Pontypridd Health Trust, for their hard work in collecting and managing project data. We are extremely grateful to our colleagues in Rhondda Cynon Taff Education Authority, and to Mr Mike Keating, Divisional Director School Support \& Improvement, for support of this project.

\section{Authors' affiliations}

W R Williams, School of Care Sciences, University of Glamorgan, UK

A H A Latif, The Children's Centre, Royal Glamorgan Hospital, UK

L Hannington, Dewi Sant Hospital, Pontypridd, UK

D R Watkins, Taff Street, Pontypridd, UK

Competing interests: none declared

\section{REFERENCES}

1 Stewart-Brown SL, Haslum MN, Butler N. Educational attainment of 10-year old children with treated and untreated visual defects. Dev Med Child Neurol 1985;27:504-13.

2 Stewart-Brown SL, Haslum MN. Screening of vision in school; could we do better by doing less? BMJ 1988;297:1111-13.

3 Hall DMB, Elliman D. Screening for vision defects. In: Health for all children, 4th edn. Oxford University Press, 2003.

4 Stewart-Brown S, Snowdon SK. Evidence-based dilemmas in pre-school vision screening. Arch Dis Child 1998;78:406-7.

5 Hartmann EE, Dobson V, Haineline L, et al. Preschool vision screening: summary of a task force report. Ophthalmology 2001;108:479-86.

6 Jayatunga R, Sonksen PM, Bhide A, et al. Measures of acuity in primary school children and their ability to detect minor errors of vision. Dev Med Child Neurol 1995;37:515-27.

7 Ciner EB, Dobson V, Schmidt PP, et al. A survey of screening policy of preschool children in the United States. Surv Ophthalmol 1999;43:445-57.

8 Strawhacker MAT, Gustafson JK, Kinne MJ, et al. Vision screening practices in central lowa: a follow up evaluation. J Sch Nurs 2003;19:111-18.

9 Kvarnstrom G, Jacobsson P, Lennerstrand G. Visual screening of Swedish children: an ophthalmological evaluation. Acta Ophthalmol Scand 2001;79:240-4.

10 Hard A-L, Sjodell L, Borres MP, et al. Pre-school vision screening in a Swedish city region: results after alteration of criteria for referral to eye clinics. Acta Ophthalmol 2002;80:608-11.

11 Garzia RP, Borsting EJ, Nicholson SB, et al. Care of the patient with learning related vision problems, Optometric Clinical Practice Guideline. St Louis, MO: American Optometric Association, 2000.

12 Benjamin WJ, ed. Borish's clinical refraction. Philadelphia: W. B. Saunders, 1998:636-8.

13 Kohler L, Stigmar G. Testing for hypermetropia in the school vision screening program. Acta Ophthalmol 1981;59:369-77.

14 Rosner J, Rosner J. The relationship between moderate hyperopia and academic achievement: how much plus is enough? J Am Optom Assoc 1997;68:648-50.

15 Cummings GE. Vision screening in junior schools. Public Health 1996;110:369-72.

16 Thomson WD, Evans B. A new approach to vision screening in schools. Ophthal Physiol Opt 1999;19:196-209.

17 Tong PY, Macke JP, Bassin RE, and The National Children's Eye Care Foundation Vision Screening Study Group, et al. Screening for amblyopia in preverbal children with photoscreening photographs. Opththalmology 2000;107:1630-6

18 Steele G, Ireland D, Block S. Cycloplegic autorefraction results in pre-school children using the Nikon Retinomax Plus and the Welch Allyn Suresight. Optom Vis Sci 2003;80:573-7.

19 Grisham JD, Simons HD. Refractive error and the reading process: a literature analysis. J Am Optom Assoc 1986;57:44-55.

20 Wharry RE, Kirkpatrick SW. Vision and academic performance of learning disabled children. Percept Mot Skills 1986;62:323-36.

21 Bamford J, Davis A, Boyle J, et al. Pre-school screening, speech, language, and vision screening. Qual Health Care 1998;7:240-7.

22 Johnson R, Nottingham D, Stratton R, et al. The vision screening of academically and behaviourally at-risk pupils. J Behav Optom 1996;7:39-46.

23 Atkinson J, Anker S, Nardini $M$, et al. Infant vision screening predicts failures on motor and cognitive tests up to school age. Strabismus 2002;10:187-98. 